\title{
Investigation on Monitoring System for Pantograph and Catenary Based on Condition-Based Recognition of Pantograph
}

\author{
Ning Zhou $\mathbb{D}^{1},{ }^{1}$ Wenjie Yang, ${ }^{1}$ Jiurui Liu, ${ }^{1}$ Weihua Zhang, ${ }^{1}$ and Dong Wang ${ }^{2}$ \\ ${ }^{1}$ State Key Laboratory of Traction Power, Southwest Jiaotong University, Chengdu 610031, China \\ ${ }^{2}$ CCRC Co., Ltd., Changchun 201102, China \\ Correspondence should be addressed to Ning Zhou; zhou_ningbb@sina.com
}

Received 26 July 2019; Revised 30 October 2019; Accepted 4 November 2019; Published 28 November 2019

Guest Editor: Franco Concli

Copyright (c) 2019 Ning Zhou et al. This is an open access article distributed under the Creative Commons Attribution License, which permits unrestricted use, distribution, and reproduction in any medium, provided the original work is properly cited.

In recent years, the length of electrified railway systems has increased along with the number of railway vehicles in China. For the pantograph-catenary system, as one of the key components of the vehicle system, an urgent problem includes diagnosing faults and proposing a safety monitoring system to assure safe operation, improve the level of detection, and decrease the cost of maintenance and repairs. For the monitoring system based on the pantograph, the design process, whole architecture, function module, fault diagnosis method, and monitoring scheme have been investigated. Two specified faults were introduced to describe how to develop such a monitoring scheme based on the pantograph condition-based recognition.

\section{Introduction}

By 2020, the total length of subway systems in China is predicted to reach $6000 \mathrm{~km}$. An increasing number of subway trains have been put into operation in many cities in China. It is very critical to peoples' livelihoods to guarantee the safe operation of these subway trains. The safe operation of these trains requires a high level of dynamical performance and reliability from pantograph and catenary systems. So, a system to monitor the dynamic performance, status, and safe operation is needed.

Progress has been made in research on condition-based monitoring and fault diagnosis of pantograph and catenary systems. More attention has been paid to the monitoring of the contact status of the pantograph and catenary system and pantograph vibration as important indices to evaluate the dynamical performance and current-collection quality $[1,2]$. In recent years, new methods to measure and process the contact status and acceleration have been presented, including image processing (visible light, ultraviolet ray, or infrared ray detection) [3-7], the vibration mode superposition and inversion $[8,9]$, and optical fibre among others.

Furthermore, through these indices, the relationship between service performance and different defects has been investigated and identified. For instance, the conditions of the overhead contact line including contact wire height, contact wire wear, contact wire stress/strain, and contact loss ratio were diagnosed as potentially problematic based on the contact force amplitude and fluctuation [10,11]. A procedure to predict the wear of the collector strip and the contact wire was established based on the contact force in pantograph and catenary systems [12]. And, another procedure to diagnose the distributed defect of the overhead line (OHL) has been proposed through the estimated contact force from pantograph motion [13].

On the other hand, optical sensors based on fibre Bragg grating (FBG) technology have been proposed as a reliable and safe solution in this type of monitoring because they have the advantages of having low loss relative to the fibre length, immunity to electromagnetic and radio frequency interference, small size and weight, safe operation capabilities in environments with hazardous materials, high sensitivity, and long-term reliability. This makes them the natural alternative to conventional electrical-sensing technologies [14-16]. In recent years, many efforts have been made to develop monitoring systems based on optical sensors. Some new optic fibre sensors that monitor the contact force of the pantograph and catenary were developed 
and validated through the laboratory tests [17]. The application of optic fibre sensors on pantograph-catenary systems was discussed, and the approach to monitor pantograph-catenary interaction was proposed in mainline railways through contact forces and accelerations, etc. [18, 19]. The same efforts to improve pantograph-catenary system monitoring have also been made in underground lines [20, 21]. Through the measurement of collector accelerations of the pantograph head using optical fibre sensors, the local defects of the overhead lines were identified based on the root mean square value of the acceleration of the collectors, and the distributed defects were detected based on the relationship between the contact forces and overhead line irregularities [22].

However, there have been few published articles on how to understand the characteristics of different failure behaviors of the pantograph and catenary system and the influence of different defects on the dynamical performance of the pantograph-catenary system. Therefore, the objective of this research is to investigate the different failure behaviors of the pantograph and catenary system and find a method to identify specific defects of the pantograph and catenary through condition-based monitoring of the pantograph, diagnose the operational status, and predict the health of the structure in advance.

\section{System Architecture}

A condition-based monitoring system of a pantograph has been established, including the on-board system, the data processing center, and server on the ground and the server in the cloud. The architecture of this monitoring system is shown in Figure 1. As an important subsystem, the on-board system mainly consists of several modules including sensor and data collection modules, a positioning module, data analysis and diagnosis modules, and display and data storage modules, and so on.

2.1. Sensor and Data Collection Module. This module is used to collect the strain, acceleration, and image data through the optical fibre sensors and the binocular vision camera. The collected data are pretreated by the processors and sent to the host computer through carriage cables and a multifunction vehicle bus. Figure 2 shows the data layer and structure of the on-board monitoring system.

2.2. Positioning Module. A global positioning system (GPS)/ inertial navigation system combination navigation is used in this system, including three gyroscopes and accelerators, through coupled GPS and inertial measurement unit technology to provide $3 \mathrm{D}$ location information, speed, and posture of the train. The collected information includes the following:

(1) Location: latitude, longitude, and altitude relative to the ground, accuracy of single point $<5$ meter

(2) Speed: accuracy in the $X, Y$, and $Z$ direction, $0.02 \mathrm{~m} / \mathrm{s}$

(3) Posture: roll angle, pitch angle, azimuth angle, accuracy: $\pm 0.015^{\circ}, \pm 0.015^{\circ}$, and $\pm 0.05^{\circ}$

(4) Data fresh frequency: $\leq 100 \mathrm{~Hz}$.
2.3. Data Analysis and Diagnosis Module. First, the data analysis and diagnosis module needs to communicate with the processor and then send the command to collect and process the signal data. Then, these data treated by the processor are sent to the data analysis and diagnosis through the cable. This results in further processing and analysis, including time and frequency domain, mathematical statistics, compatibility between different operation periods and trains, tendency prediction, and so on. More importantly, these data on dynamical performance are carefully identified through the diagnostic model to determine whether there is a fault in this system. Thus, the operation status of the pantograph-catenary system is assessed, and the real-time status information and the health are promptly sent to the multiple intelligent control unit (MICU) of the train and other modules for the next steps.

2.4. Display and Data Storage Module. The characteristic data and the operation status information of the pantograph-catenary system may be transmitted to the display and storage system in the driver's cab based on the existing and embedded network in the train. The driver may inspect the real-time information of the monitoring system and accordingly take necessary action under the guidance of the expert system. Except for the characteristic data and status information, the raw data may also be stored in the on-board server and periodically sent to a big data processing center on the ground through an Ethernet network or a hard disk copy for further processing and analysis.

In addition, through wireless connections to the server in the cloud, except in the driver's cab and data processing center on the ground, users may also inspect the monitoring information through a remote terminal device. Users could find some problem promptly and give a timely feedback based on the "normal," "alarm," or other operational status, etc., to improve safety management.

\section{Catenary Monitoring}

3.1. Fault Description of Catenary System. In general, the irregularity of the contact wire and faults of the catenary system come from many different factors, such as expansion joint defects, overlap defects, and steady arm defects. These catenary defects may induce hard impacts on the dynamic interaction, which result in not only mechanical damage to the pantograph and local abnormal wear of the contact wire, but also the failure of the pantograph-catenary system and a reduction in its service life [23-26]. Thus, it is necessary to facilitate an effective monitoring scheme and an accurate diagnostic method to locate the defects and diagnose breakdowns for the safe operation of the train.

3.2. Monitoring Scheme. Following the methods described in reference [27], four optic fibre strain sensors were divided into two groups (sensors 1, 2 and sensors 3, 4), and were respectively embedded into the aluminum support at a distance of $250 \mathrm{~mm}$ from the corner of the pantograph collector, as shown in Figure 3. These sensors are extremely 


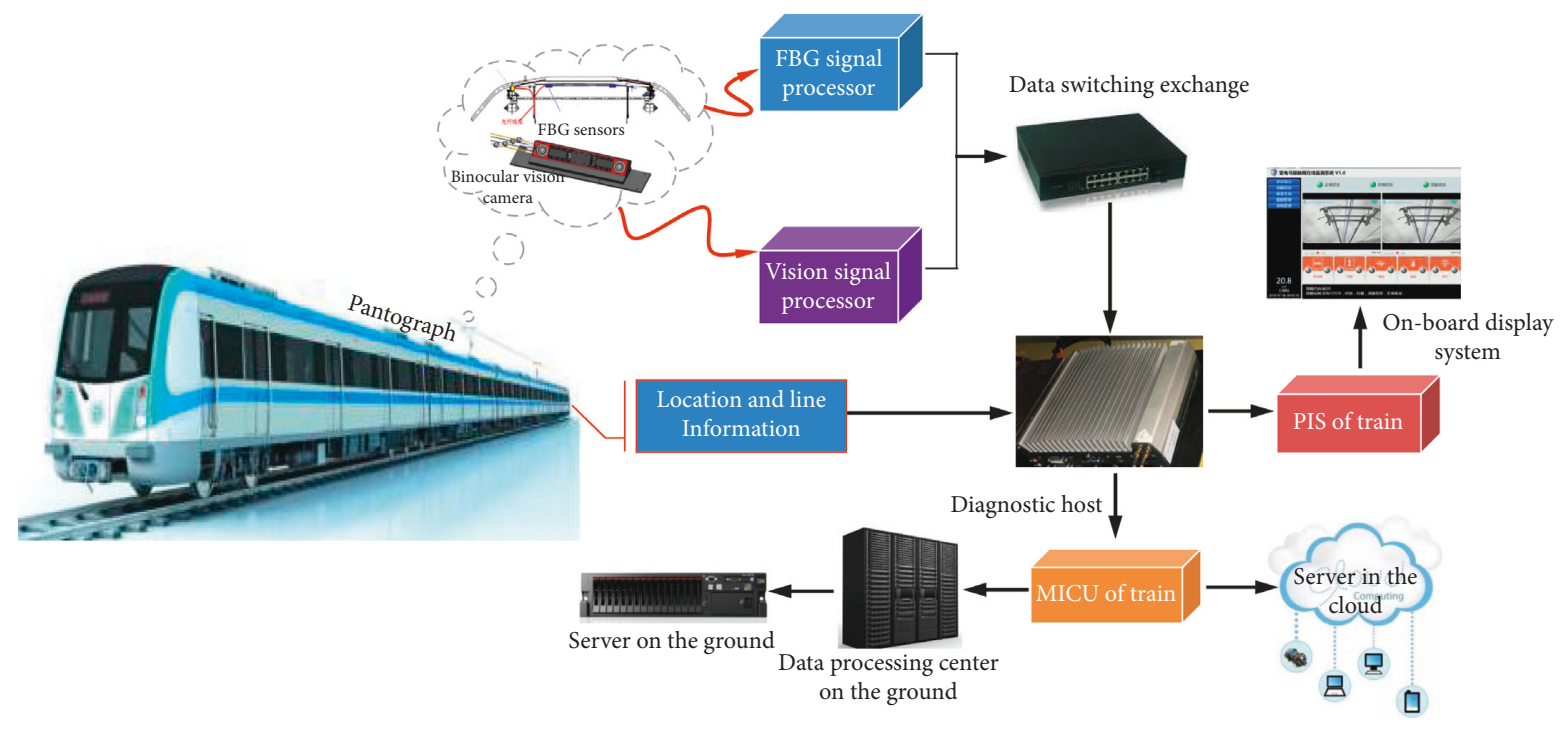

Figure 1: Architecture of the pantograph monitoring system.
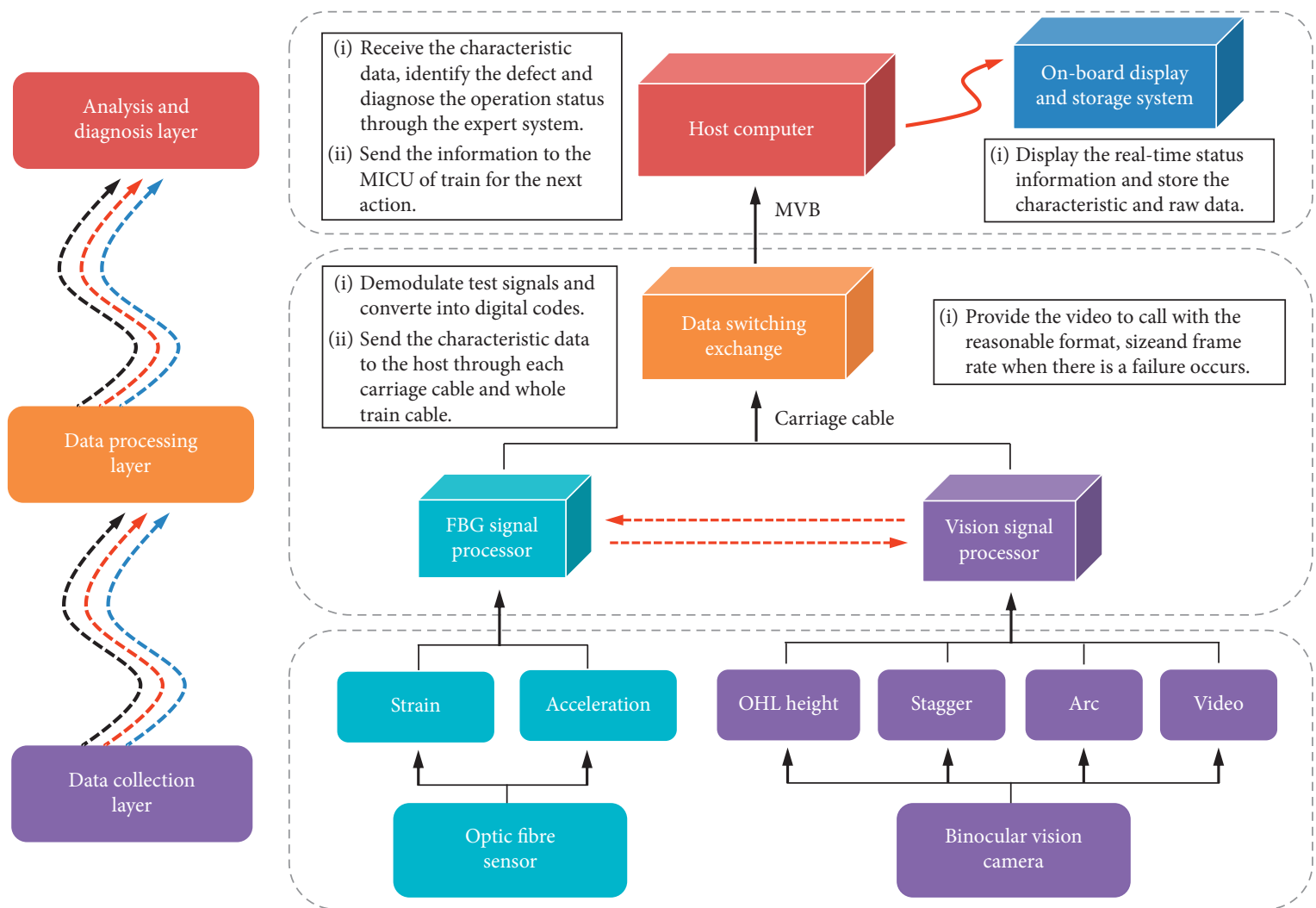

FIgURE 2: Data layer and structure diagrams of the on-board system.

small, with a mass of $10 \mathrm{~g}$ with dimensions of $20 \times 5 \times 1 \mathrm{~mm}^{3}$, and are used to measure the collector strain of the pantograph. They have no obvious effect on the dynamic performance of the pantograph. The measurement frequency of the optic fibre strain sensors is up to $25 \mathrm{kHz}$, the measuring range is $\pm 2000 \mu \varepsilon$, and the sensitivity coefficient is $0.8 \mu \varepsilon / \mathrm{pm}$ with a wide measuring range and high precision. The measured signals are collected with a sampling frequency of $500 \mathrm{~Hz}$ and demodulated into strain signals. Moreover, because the FBG-based sensors are sensitive to both strain and temperature, the reference temperature sensors for temperature compensation are mounted near the strain sensors to improve the measurement accuracy.

For FBG strain sensors and traditional force sensors, the comparison and the validation have been carried out. Based on the pantograph-catenary test rig, the collector of the pantograph was excited through the actuator at the different frequencies, as shown in Figure 4. Furthermore, the 


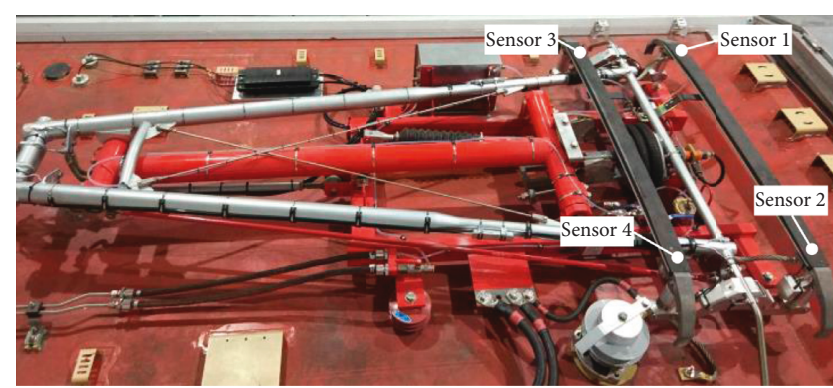

(a)

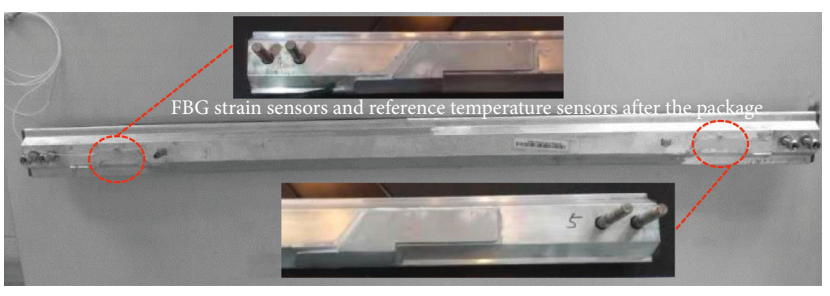

(b)

FIGURE 3: Sensor configuration (sensors 1-4 are the FBG strain sensors and their reference temperature sensors after the package).

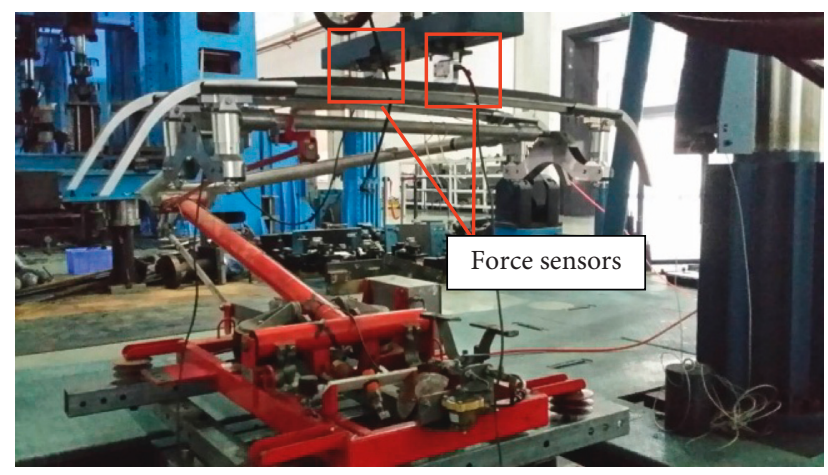

(a)

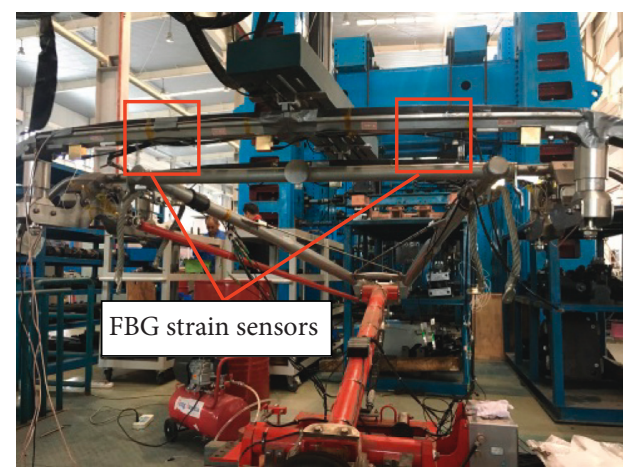

(b)

FIgURE 4: Pantograph in the dynamic test.

measured and deduced contact forces through the strains were compared with the obtained force based on the force sensor fixed on the head of the actuator. Here, the results of contact forces in Figure 5 are presented at the frequency of $5 \mathrm{~Hz}$ and $10 \mathrm{~Hz}$. Moreover, Table 1 shows the statistical results of contact forces. The contact forces through the two kinds of methods have a good consistency. In addition, there is no obvious difference in the maximum and the minimum of contact forces, and the relative error of the maximum and the minimum is, respectively, $1.54 \%$ and $3.12 \%$. So, the indirect method through the strain measurement may be used to determine the contact forces between the pantograph and catenary.

\subsection{Diagnostic Method}

3.3.1. Signal Processing. The measured strain signals are first compensated by means of reference temperature sensors and low-pass filtered with a $20 \mathrm{~Hz}$ cutoff frequency [28]. Then, the standard deviation (STD) of the strain signals is directly calculated over a short mobile window by using time samples to quantify the variation or dispersion of a set of data values [22]. Therefore, this mobile standard deviation (MSTD) of the strain signals, defined as equation (1), is used to strengthen the identification of the impact peaks caused by the catenary defects:

$$
\operatorname{MSTD}\left(i+\frac{\text { win }}{2}-1\right)=\operatorname{STD}_{i}^{i+\text { win-1 }}, \quad(1 \leq i \leq N-\text { win }+1)
$$

where $N$ is the total number of sampling points $i$ and win is the size of the mobile window ( win $=\mathrm{Ts} \times \mathrm{Fs}$, in which Ts and Fs are the time window and sampling frequency, respectively).

Furthermore, the mean mobile standard deviation (MMSTD) over a mobile window of a larger length (win $P$ ) than win is specifically calculated by equation (2) to determine the actual abnormal impact based on the mobile adaptive Pauta criterion:

$$
\begin{array}{r}
\operatorname{MMSTD}\left(i+\frac{\operatorname{win} P}{2}-1\right)=3 \cdot \frac{1}{\operatorname{win} P} \sum_{i}^{i+\operatorname{win} P-1} \operatorname{MSTD}(i), \\
\quad(1 \leq i \leq N-\operatorname{win} P+1)
\end{array}
$$

where a long window length ( $\operatorname{win} P=50 \times$ win) is selected to average the increased vibration of the pantograph-catenary interaction and judge the actual impact. Thus, the judgment of normal and abnormal signals is obtained by comparing the data of the same sample at different times through the mobile window. Different from previous-fixed thresholds, the proposed MMSTD method adaptively adjusts the 
TABLE 1: Statistical results of contact forces in dynamical test.

\begin{tabular}{|c|c|c|c|c|c|c|c|c|c|c|c|c|}
\hline \multirow{3}{*}{$\begin{array}{l}\text { Frequency } \\
(\mathrm{Hz})\end{array}$} & \multicolumn{12}{|c|}{ Contact force $(\mathrm{N})$} \\
\hline & \multicolumn{3}{|c|}{ Mean } & \multicolumn{3}{|c|}{ Min } & \multicolumn{3}{|c|}{ Max } & \multicolumn{3}{|c|}{ Standard deviation } \\
\hline & $\begin{array}{c}\text { Real } \\
F_{a}\end{array}$ & $\begin{array}{l}\text { Test } \\
F_{m}\end{array}$ & $\begin{array}{c}\text { Relative error } \\
(\%)\end{array}$ & $\begin{array}{c}\text { Real } \\
F_{a}\end{array}$ & $\begin{array}{l}\text { Test } \\
F_{m}\end{array}$ & $\begin{array}{l}\text { Relative error } \\
(\%)\end{array}$ & $\begin{array}{c}\text { Real } \\
F_{a}\end{array}$ & $\begin{array}{l}\text { Test } \\
F_{m}\end{array}$ & $\begin{array}{c}\text { Relative error } \\
(\%)\end{array}$ & $\begin{array}{c}\text { Real } \\
F_{a}\end{array}$ & $\begin{array}{l}\text { Test } \\
F_{m}\end{array}$ & $\begin{array}{c}\text { Relative error } \\
(\%)\end{array}$ \\
\hline 2 & 120.28 & 120.20 & 0.07 & 110.10 & 110.31 & 0.19 & 136.41 & 136.56 & 0.11 & 5.81 & 5.82 & 0.17 \\
\hline 5 & 120.70 & 120.89 & 0.16 & 54.34 & 52.83 & 2.78 & 172.49 & 173.08 & 0.34 & 27.29 & 29.26 & 7.22 \\
\hline 8 & 119.25 & 121.08 & 1.53 & 52.21 & 47.21 & 2.80 & 177.47 & 175.74 & 0.96 & 27.20 & 27.38 & 0.66 \\
\hline 10 & 118.71 & 120.87 & 1.82 & 50.20 & 48.63 & 3.12 & 183.10 & 185.92 & 1.54 & 26.17 & 28.91 & 10.47 \\
\hline
\end{tabular}

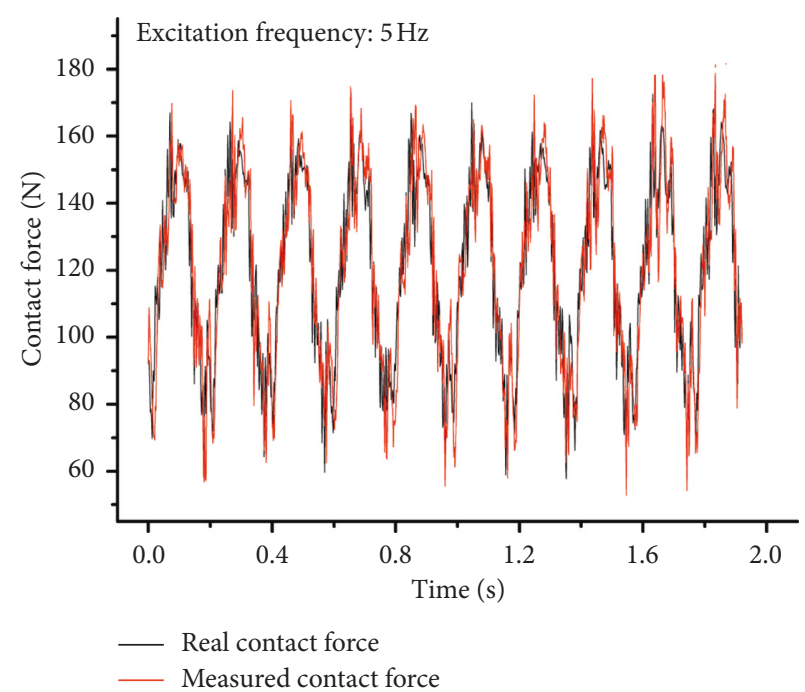

(a)

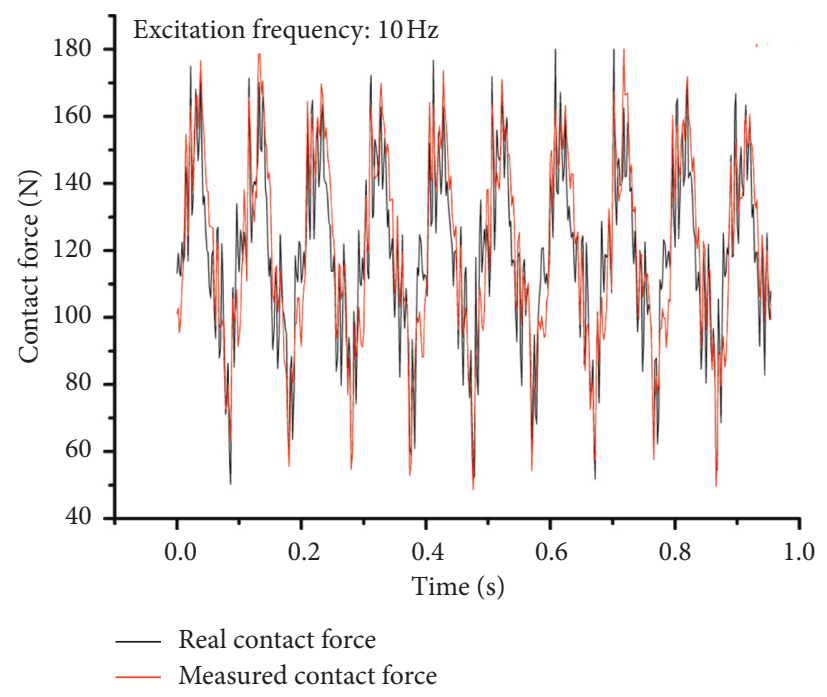

(b)

Figure 5: Comparison of contact forces. (a) $5 \mathrm{~Hz}$. (b) $10 \mathrm{~Hz}$.

judgment index, reduces the misjudgment rate of impact, and improves the accuracy of impact recognition.

3.3.2. Defect Detection. As an example, Figure 6 shows the strain signals of the four optic fibre sensors after the temperature compensation, $20 \mathrm{~Hz}$ low-pass filter, and the mobile STD values through the signal processing in the actual operation section. This section includes two overlap sections (marked by a red box), ten expansion joints, and eleven midpoint anchors. Since the actual catenary defects will inevitably cause impacts on both the front and rear collectors, that is, only four strain signals are simultaneously identified with impacts, each identified impact is a real impact defect. Therefore, through the mobile STD (black curve) and the mobile Pauta criterion (red curve), the real impact defects $(1,2$, $3,4,5,6$, and 7) can be effectively identified from the strain background. Furthermore, for two kinds of specific defects, the methods to locate the defects and diagnose the cause of the problem through the strain signal can be determined.

(1) Detection of Defects Caused by Expansion Joints. In order to facilitate the smooth transition of the stagger of two adjacent conductor rails, the expansion joint is generally installed in a position where the stagger is zero on account of the installation requirement. On basis of this characteristic, the measured left and right strain values are zero, which helps to locate the expansion joint. When there are defects in the expansion joint at the two adjacent conductor rails, impacts are inevitably generated and a high peak appears in the strain signal. Thus, based on these features, positions 2, 3, 4, 5, and 6 in Figure 6 have stagger values close to zero and are identified as expansion joints. This is also consistent with the construction plan.

(2) Detection of Defects Caused by Overlaps. When the pantograph passes through the overlap sections, it will make the measured values of the left and right strains rapidly change from one direction to another. An impulse signal in the strain is generated. It is this feature that helps locate the overlap section based on the measured strain signals. In Figure 6, the strain signals at position 1 (at 2070s) and 7 (at 2210s) rapidly vary from one direction to another and were distinguished as overlap sections. This was verified by comparison with the construction plan of the catenary. But if there is not only one impulse signal, this section would be considered a defective overlap section. The extra impulse signal is contributed by an overlap defect, like a misaligned overlap. 


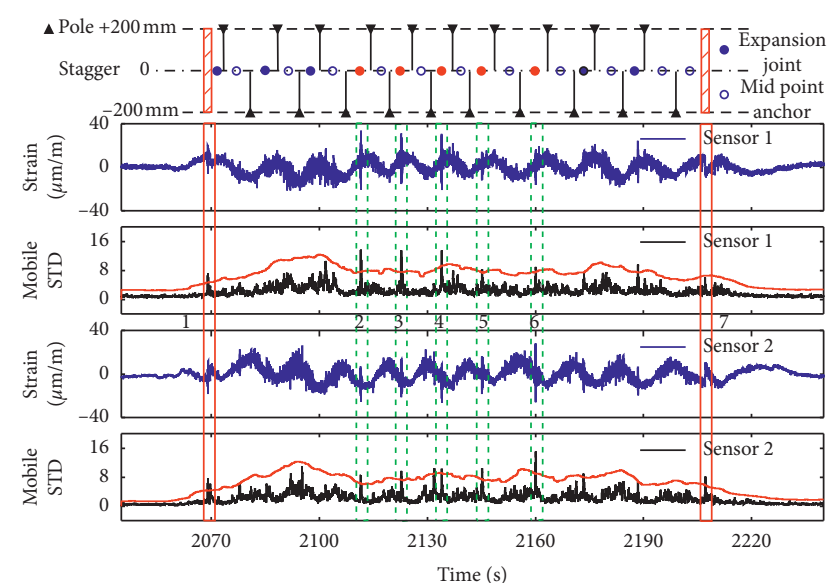

(a)

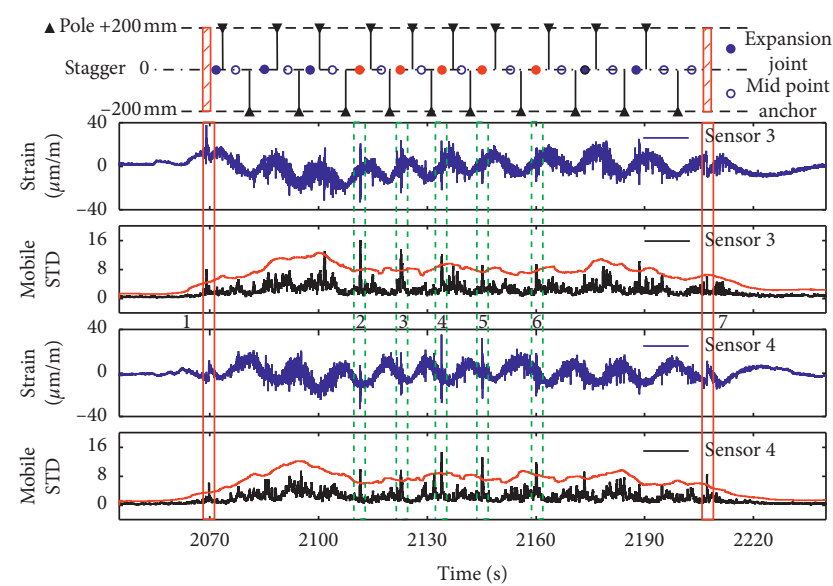

(b)

FIGURE 6: Processed strain signals and the mobile STD during regular operation (the time window Ts is 0.2 s). (a) Front collector. (b) Rear collector.

Thus, when impacts on the pantograph and catenary system are identified based on the mobile STD combined with the mobile Pauta criterion during the operation of the train, the four strain signals from the pantograph can locate the catenary defects and diagnose the problem.

\section{Pantograph Monitoring}

4.1. Fault Description of Pantograph. The pantograph can fail in many different ways including upper frame cracks, suspension system damage, pull rod fractures, and operating system failure, and so on. The pull rod of the pantograph is generally assumed as a two-force rod, and then the intensity and fatigue design is performed, only considering the axial draw and pressure loads. In other words, if there is only an axial load, the pull rod is strong enough to withstand the heavy load. However, the pull rod failure is actually observed, for example, fractures in the outer rings and the pretension bolt fractures. Figure 7 shows that the outer rings of the joint bearing of the pull rod were ripped during operation of the underground line.

4.2. Monitoring Scheme. Two groups of optic fibre strain sensors have been attached on the top and the bottom surface of the pull rod close to the connections with the upper arm and the base, as shown in Figure 8.

The strains of the two sampling points on section 1 and section $2, \varepsilon_{t 1}, \varepsilon_{b 1}$ and $\varepsilon_{t 2}, \varepsilon_{b 2}$ may be determined. Thus, the relation of stress and strain may be written as follows:

$$
\begin{aligned}
& \sigma_{t 1}=\frac{F_{n 1}}{A}-\frac{M_{1}}{W_{Z}}=E \varepsilon_{t 1}, \\
& \sigma_{b 1}=\frac{F_{n 1}}{A}+\frac{M_{1}}{W_{Z}}=E \varepsilon_{b 1}, \\
& \sigma_{t 2}=\frac{F_{n 2}}{A}-\frac{M_{2}}{W_{Z}}=E \varepsilon_{t 2}, \\
& \sigma_{b 2}=\frac{F_{n 2}}{A}+\frac{M_{2}}{W_{Z}}=E \varepsilon_{b 2},
\end{aligned}
$$

where $\sigma_{t 1}, \sigma_{b 1}$ and $\sigma_{t 2}, \sigma_{b 2}$ are the normal stress of two sampling points on section 1 and section $2, F_{n 1}$ and $F_{n 2}$ is the normal force on section 1 and section $2, A$ is the section area, $M_{1}$ and $M_{2}$ is the bending moment on section 1 and section 2, $W_{z}$ is the coefficient of the bending section, and $E$ is the elastic module.

Moreover, through the pull force of the two sampling points on section $2, F_{t 2}$ and $F_{b 2}$, the normal force $F_{n 2}$ and the bending moment $M_{2}$ on section 2 may be deduced as follows:

$$
\begin{aligned}
& F_{n 2}=\frac{1}{2}\left(\varepsilon_{t 2}+\varepsilon_{b 2}\right) E A=\frac{1}{2}\left(F_{t 2}+F_{b 2}\right), \\
& M_{2}=\frac{1}{2} \frac{\left(F_{b 2}-F_{t 2}\right)}{A} W_{Z} .
\end{aligned}
$$

Furthermore, based on the applied force equilibrium analysis of the separate body between sections 1 and 2, the tangential force $F_{v 2}$ on section 2 may be obtained:

$$
F_{V 2}=\frac{\left(M_{1}-M_{2}\right)}{L_{12}} \text {. }
$$

Then, for the separate body between sections 2 and 3, the bending moment on section $3, M_{3}$, may be determined, and $L_{23}$ is the distance between sections 2 and 3, as follows:

$$
M_{3}=M_{2}-F_{V 2} L_{23} \text {. }
$$

Meanwhile, the corresponding stress may also be obtained on section 3 , through the following equation:

$$
\sigma_{3}==\frac{F_{V 2} L_{23}-M_{2}}{W_{z 3}}+\frac{F_{n 2}}{A_{3}},
$$

where $W_{z 3}$ is the coefficient of the bending section 3 and $A_{3}$ is the area of section 3 .

Thus, through the measured strains at the sampling points, the axial force and the bending moment and the normal stress of all sections may be deduced and monitored, especially at the hot spot of damage, such as the bearing outer ring and the bolt connection. 


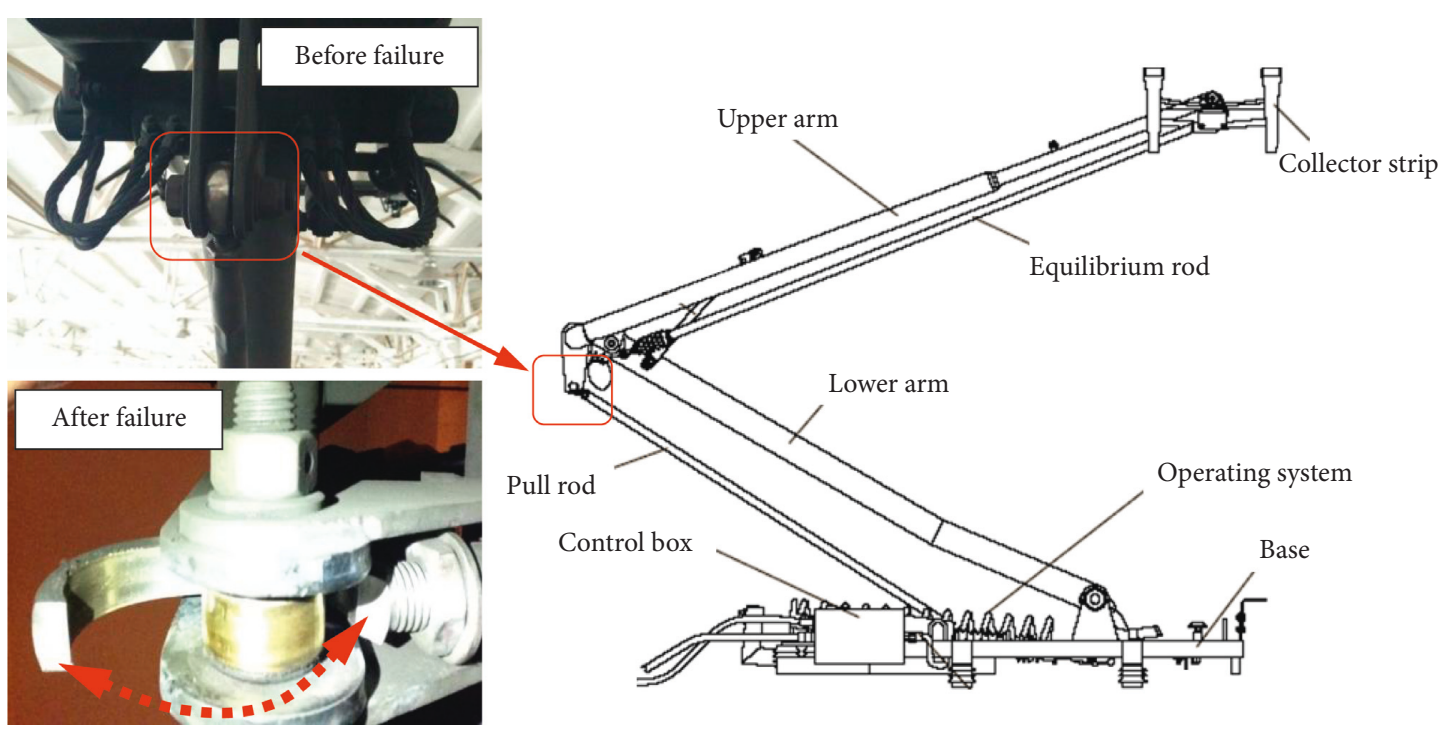

Figure 7: Damaged outer rings of the joint bearing of the pull rod.

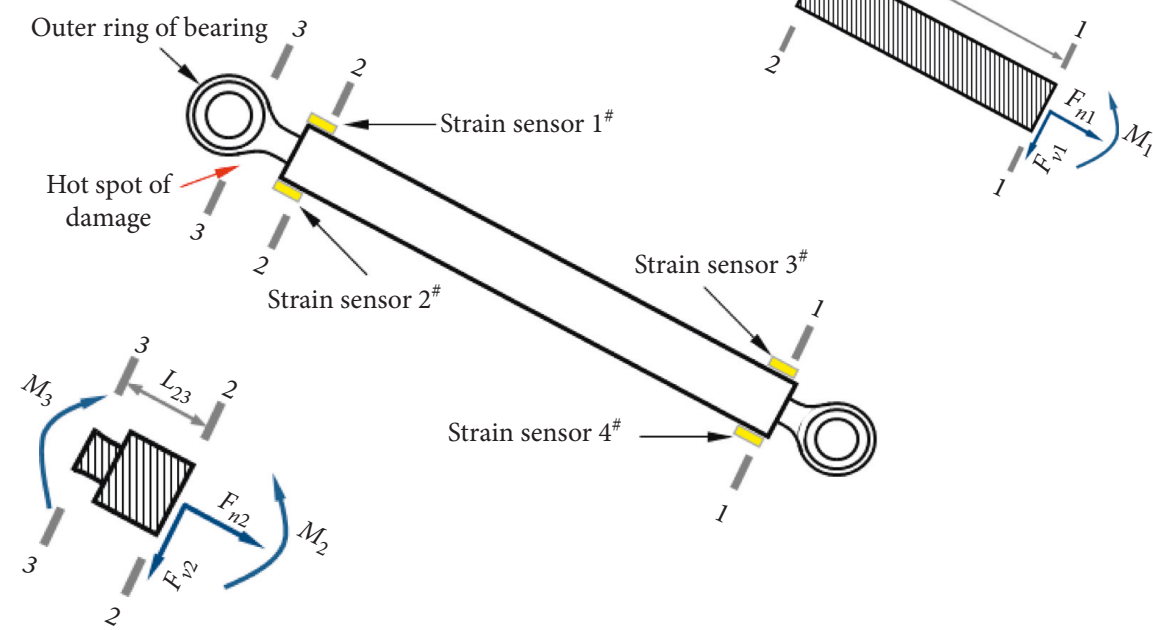

Figure 8: Applied force analysis of pull rod.

4.3. Diagnostic Method. Figure 9 shows the calculated pull force through the measured strain on the top and bottom surfaces of two different kinds of pull rods for the same pantograph, at $80 \mathrm{~km} / \mathrm{h}$. During the actual operation, the pull forces at the two sampling locations are not equal and fluctuate in an opposite trend. This indicates that there is bending deformation which causes the difference in the pull force on the top and bottom surface, in cases where the torsion deformation has been limited and excluded in advance. Moreover, the maximum of two pull forces are $9209.67 \mathrm{~N}$ and $9660.66 \mathrm{~N}$, respectively. Both of them are much less than the allowable values of the axial loads, as mentioned above. Thus, the destruction of the pull rod is not caused by the axial force alone, but it is caused by the combined action of the axial force and the bending moment.
At about $580 \mathrm{~s}$, the working height of the pantograph changed from the rigid section to the flexible section of the overhead line, causing a break point in the pull forces.

The pull force of the type A pull rod in Figure 9(a) shows a more violent fluctuation than that of type B in Figure 9(b). This also leads to an undesirable bending moment, closely related to the deviation of the pull forces on the top and bottom surfaces, compared to type B. It is also verified that through the actual service situation, the service life of type B is exactly longer than that of type A.

Figure 10 shows the axial force and the bending moment at the hot spot of damage for the pull rod at the speed of $80 \mathrm{~km} / \mathrm{h}$. For the different pull rods, a different bearing force status may be found, including the axial forces and the bending moments. 


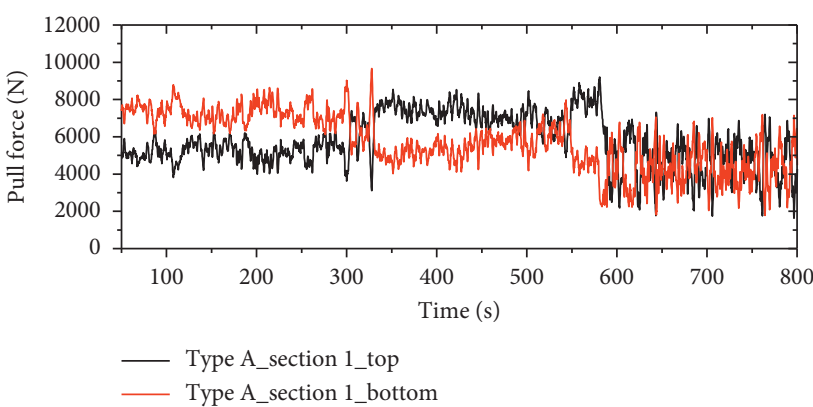

(a)

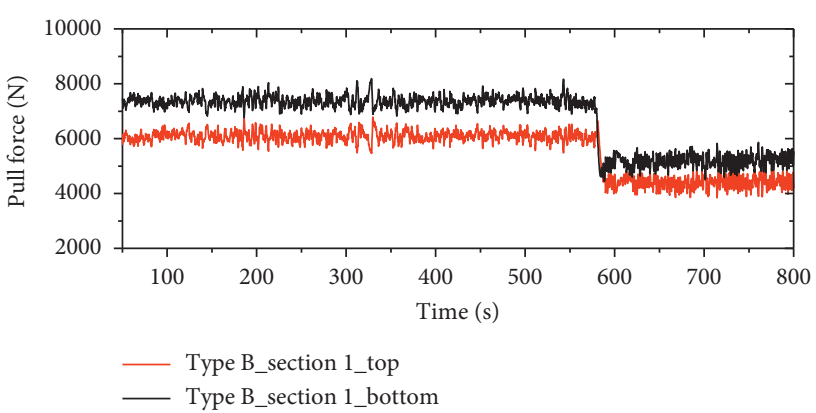

(b)

Figure 9: Pull forces on the top and bottom surfaces of two different kinds of pull rods. (a) Type A. (b) Type B.

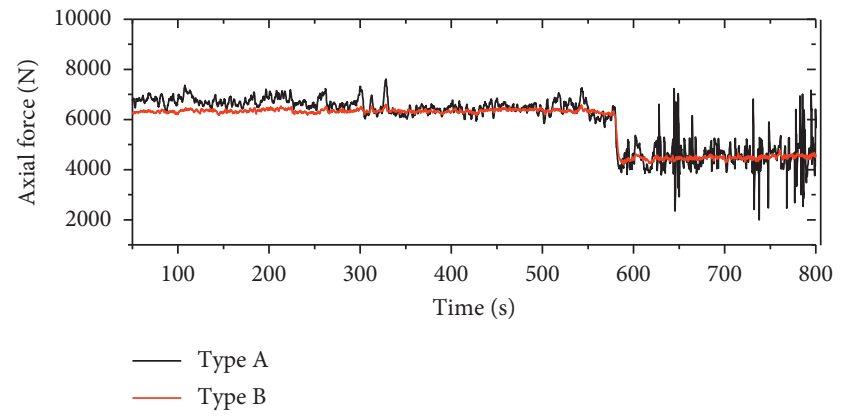

(a)

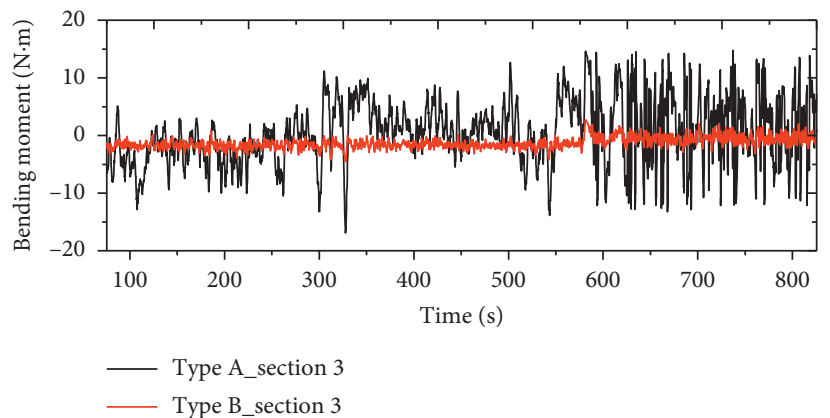

(b)

Figure 10: Axial force and bending moment of two different kinds of pull rods. (a) Axial force. (b) Bending moment.

TABLE 2: Statistical results of the axial forces and the bending moments.

\begin{tabular}{lccccc}
\hline & Type & Mean & Min & Max & Dev. \\
\hline \multirow{2}{*}{ Axial force (N) } & A & 6581.33 & 5684.84 & 7610.96 & 6607.91 \\
\hline \multirow{2}{*}{ Bending moment (N.m) } & B & 6342.75 & 6157.13 & 63.86 \\
& A & -0.57 & -16.89 & 12.66 \\
\hline
\end{tabular}

The statistical results of the axial forces and the bending moments for the rigid section of the overhead line (about from $50 \mathrm{~s}$ to $570 \mathrm{~s}$ ) are shown in Table 2. Compared to the axial forces of the two kinds of the pull rods, there is the more obvious difference in the bending moments. Especially, the minimum, maximum, and standard deviation of the bending moment of the type A pull rod is much larger than those of type $\mathrm{B}$. The bending moment of the type A pull rod shows a more violent fluctuation than that of type $B$. Therefore, the bending moment, as a monitored indicator, may more effectively reflect the service performance of the pull rod. The lower mean and fluctuation in the bending moments of the pull rod results in better service performance.

Moreover, Figure 11 shows the axial stress, bending stress, and normal stress at the same conditions for two kinds of the pull rods. For the rigid section of the overhead line, the statistical results of the axial stress, bending stress, and normal stress are shown in Table 3.
It can be seen that for the rigid section of the overhead line, the mean of the axial stress and the standard deviation of the bending stress are more approximate to the homologous value of the normal stress, respectively. This indicates that the axial stress and the bending stress, respectively, play an important role in the mean and the fluctuation amplitude of the normal stress. Yet it is the fluctuation in the normal stress, closely related to the bending stress that has a heavy influence of the fatigue life of the pull rod.

Hence, through strain monitoring, the axial force and the bending moment are obtained. The corresponding axial stress, bending stress, and normal stress at the hot spot of damage are identified and judged through the allowable stress limit of this material and the history big data. The fatigue strength and service life of the pull rod are also assessed. Furthermore, the operation status of the pull rod is diagnosed and the health of the structure may be predicted in advance. 


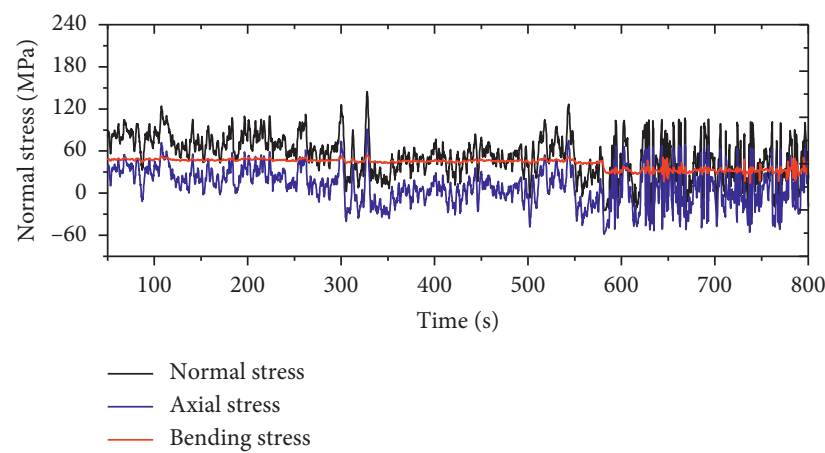

(a)

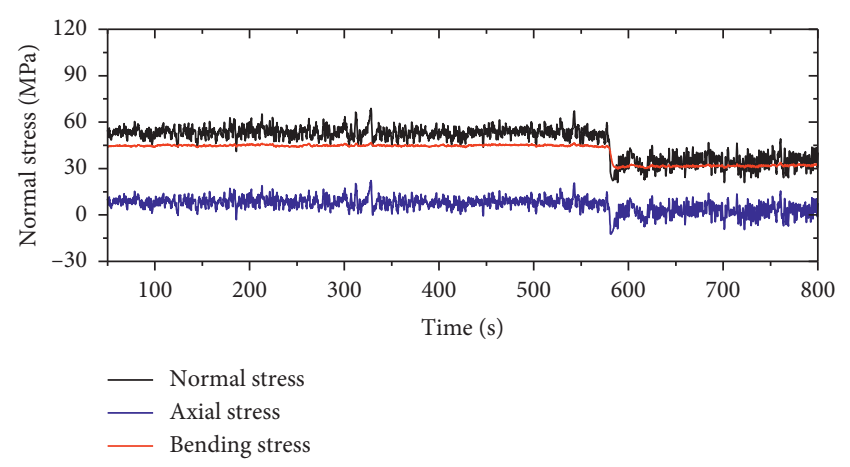

(b)

FIgURE 11: Axial stress, bending stress, and normal stress for two kinds of the pull rods. (a) Type A. (b) Type B.

TABLE 3: Statistical results of the axial stress, bending stress, and total stress.

\begin{tabular}{|c|c|c|c|c|c|}
\hline \multirow{2}{*}{ Type } & \multirow{2}{*}{ Name } & \multicolumn{4}{|c|}{ Stress/MPa } \\
\hline & & Mean & Min & Max & Dev. \\
\hline \multirow{3}{*}{ A } & Axial stress & 46.57 & 40.23 & 53.86 & 1.97 \\
\hline & Bending stress & 13.89 & -48.20 & 90.97 & 22.41 \\
\hline & Normal stress & 60.46 & -6.85 & 144.57 & 24.34 \\
\hline \multirow{3}{*}{ B } & Axial stress & 44.88 & 43.57 & 46.76 & 0.45 \\
\hline & Bending stress & 8.45 & -2.97 & 22.16 & 3.08 \\
\hline & Normal stress & 53.33 & 41.03 & 68.92 & 3.42 \\
\hline
\end{tabular}

\section{Conclusion}

In this paper, some characteristics of different failure behaviors of the pantograph and catenary and the influence of the structure defects on the dynamical performance of the pantograph-catenary system were investigated. A pantographcatenary monitoring system is established, including sensor and data collection modules, positioning modules, data analysis and diagnosis modules, and display and data storage modules. For the specified defects of the catenary and failure behavior of the pantograph, the monitoring method is presented to identify some common defects of the pantograph and catenary, diagnose the operation status, and predict the health of the structure in advance. The failures were detected by the proposed detection system and verified by the construction plan of the catenary as well as manual inspection results, demonstrating the effectiveness of the detection system.

\section{Data Availability}

The strain, stress, force, and moment data used to support the findings of this study are available from the corresponding author upon request.

\section{Conflicts of Interest}

The authors declare that they have no conflicts of interest.

\section{Acknowledgments}

This work is supported by the National Key Research and Development Program of China under grant number 2017 YFB1201201.

\section{References}

[1] J. S. Kim, "An experimental study of the dynamic characteristics of the catenary-pantograph interface in high speed trains," Journal of Mechanical Science and Technology, vol. 21, no. 12, pp. 2108-2116, 2007.

[2] C. K. Park, Y. G. Kim, Y. H. Cho et al., "Development of force sensor to measure contact force of pantograph for high-speed train," Journal of the Korean Society for Railway, vol. 13, no. 5, pp. 488-492, 2010.

[3] T. Koyama, M. Ikeda, K. Nakamura et al., "Measuring the contact force of a pantograph by image processing technology," Computers in Railways XIII: Computer System Design and Operation in the Railway and Other Transit Systems, vol. 127, pp. 189-198, 2012.

[4] T. Koyama, M. Ikeda, S. Kobayashi et al., "Measurement of the contact force of the pantograph by image processing technology," Quarterly Report of RTRI, vol. 55, no. 2, pp. 73-78, 2014.

[5] T. Hayasaka, M. Shimizu, and K. Nezu, "Development of contact-loss measuring system using ultraviolet ray detection," Quarterly Report of RTRI, vol. 50, no. 3, pp. 131-136, 2009.

[6] A. Landi, L. Menconi, and L. Sani, "Hough transform and thermo-vision for monitoring pantograph-catenary system," Proceedings of the Institution of Mechanical Engineers, Part F: Journal of Rail and Rapid Transit, vol. 220, no. 4, pp. 435-447, 2006.

[7] E. Karakose, M. T. Gencoglu, M. Karakose, I. Aydin, and E. Akin, "A new experimental approach using image processing-based tracking for an efficient fault diagnosis in pantograph-catenary systems," IEEE Transactions on Industrial Informatics, vol. 13, no. 2, pp. 635-643, 2017.

[8] M. Ikeda, S. Nagasaka, and A. U. Takayuki, "A precise contact force measuring method for overhead catenary system," in 
Proceedings of the World Congress on Railway Research 2001, Cologne, Germany, November 2001.

[9] M. Ikeda, "The Contact force between pantograph and contact wire," Quarterly Report of RTRI, vol. 45, no. 2, pp. 80-85, 2004.

[10] S. Kusumi, T. Fukutani, and K. Nezu, "Diagnosis of overhead contact line based on contact force," Quarterly Report of RTRI, vol. 47, no. 1, pp. 39-45, 2006.

[11] T. Usuda, "Estimation of wear and strain of contact wire using contact force of pantograph," Quarterly Report of RTRI, vol. 48 , no. 3, pp. 170-175, 2007.

[12] G. Bucca and A. Collina, "A procedure for the wear prediction of collector strip and contact wire in pantograph-catenary system," Wear, vol. 266, no. 1-2, pp. 46-59, 2009.

[13] A. Collina, F. Fossati, M. Papi, and F. Resta, "Impact of overhead line irregularity on current collection and diagnostics based on the measurement of pantograph dynamics," Proceedings of the Institution of Mechanical Engineers, Part F: Journal of Rail and Rapid Transit, vol. 221, no. 4, pp. 547-559, 2007.

[14] K. O. Hill and G. Meltz, "Fiber bragg grating technology fundamentals and overview," Journal of Lightwave Technology, vol. 15, no. 8, pp. 1263-1276, 1997.

[15] B. Lee, "Review of the present status of optical fiber sensors," Optical Fiber Technology, vol. 9, no. 2, pp. 57-79, 2003.

[16] A. Mendez, "Fibre bragg grating sensors: a market overview," in Proceedings of the Third European Workshop on Optical Fibre Sensors, pp. 661905-661905-6, International Society for Optics and Photonics, Napoli, Italy, July 2007.

[17] R. Wagner, D. Maicz, W. Viel et al., "A fibre optic sensor instrumented pantograph as part of a continuous structural health monitoring system for railway overhead lines," in Proceedings of the EWSHM-7th European Workshop on Structural Health Monitoring, Nantes, France, July 2014.

[18] K. Schröder, W. Ecke, M. Kautz, S. Willett, M. Jenzer, and T. Bosselmann, "An approach to continuous on-site monitoring of contact forces in current collectors by a fiber optic sensing system," Optics and Lasers in Engineering, vol. 51, no. 2, pp. 172-179, 2013.

[19] K. Schröder, M. Rothhardt, W. Ecke, U. Richter, A. Sonntag, and H. Bartelt, "Fibre optic sensing system for monitoring of current collectors and catenary of railways," in Proceedings of the GMA/ITG-Fachtagung Sensoren und Messsysteme, Nürnberg, Germany, May 2016.

[20] M. Bocciolone, G. Bucca, A. Collina et al., "An approach to monitor railway pantograph-catenary interaction with fibre optic sensors," in Proceedings of the (EWOFS'10) Fourth European Workshop on Optical Fibre Sensors, pp. 76533Q76533Q-4, International Society for Optics and Photonics, Porto, Portugal, September 2010.

[21] M. Bocciolone, G. Bucca, A. Collina, and L. Comolli, "Pantograph-catenary monitoring by means of fibre bragg grating sensors: results from tests in an underground line," $\mathrm{Me}$ chanical Systems and Signal Processing, vol. 41, no. 1-2, pp. 226-238, 2013.

[22] M. Carnevale and A. Collina, "Processing of collector acceleration data for condition-based monitoring of overhead lines," Proceedings of the Institution of Mechanical Engineers, Part F: Journal of Rail and Rapid Transit, vol. 230, no. 2, pp. 472-485, 2016.

[23] W. Zhang, Y. Liu, and G. Mei, "Evaluation of the coupled dynamical response of a pantograph-catenary system: contact force and stresses," Vehicle System Dynamics, vol. 44, no. 8, pp. 645-658, 2006.
[24] D. Zou, N. Zhou, L. Rui Ping, G. M. Mei, and W. H. Zhang, "Experimental and simulation study of wave motion upon railway overhead wire systems," Proceedings of the Institution of Mechanical Engineers, Part F: Journal of Rail and Rapid Transit, vol. 231, no. 8, pp. 934-944, 2017.

[25] S. H. Kia, F. Bartolini, A. Mpanda-Mabwe et al., "Pantographcatenary interaction model comparison," in Proceedings of the IECON 2010-36th Annual Conference on IEEE Industrial Electronics Society, pp. 1584-1589, IEEE, Glendale, AZ, USA, November 2010.

[26] J.-H. Seo, S.-W. Kim, I.-H. Jung et al., "Dynamic analysis of a pantograph-catenary system using absolute nodal coordinates," Vehicle System Dynamics, vol. 44, no. 8, pp. 615-630, 2006.

[27] M. Tan, N. Zhou, J. Wang, D. Zou, W. Zhang, and G. Mei, “A real-time impact detection and diagnosis system of catenary using measured strains by fibre bragg grating sensors," Vehicle System Dynamics, vol. 57, no. 12, pp. 1924-1946, 2019.

[28] M. Tan, N. Zhou, Y. Cheng, J. Wang, W. Zhang, and D. Zou, "A temperature-compensated fiber bragg grating sensor system based on digital filtering for monitoring the pantograph-catenary contact force," Proceedings of the Institution of Mechanical Engineers, Part F: Journal of Rail and Rapid Transit, vol. 233, no. 2, pp. 187-200, 2019. 


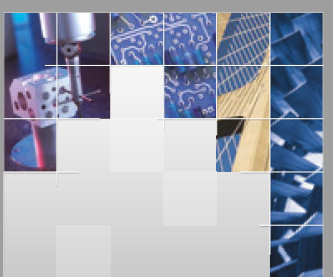

\section{Enfincering}
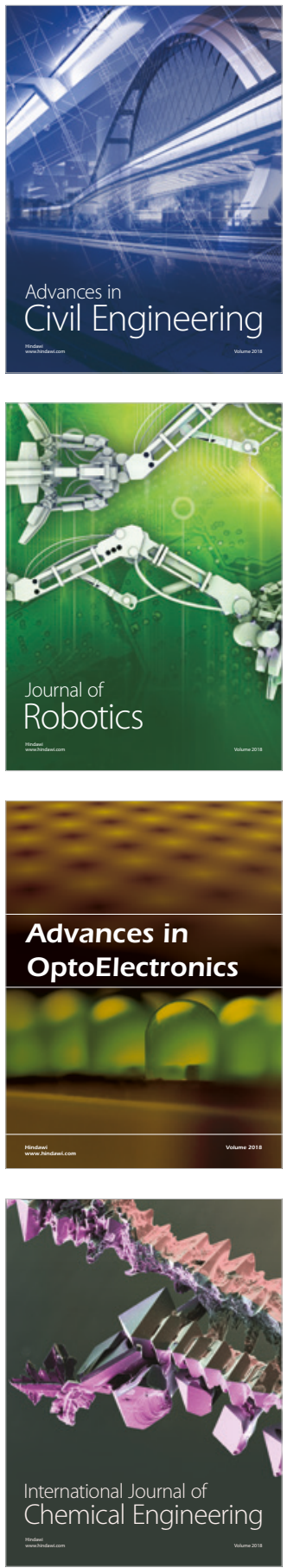

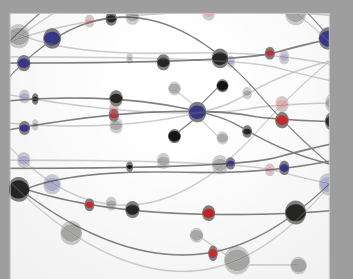

\section{Rotating \\ Machinery}

The Scientific World Journal

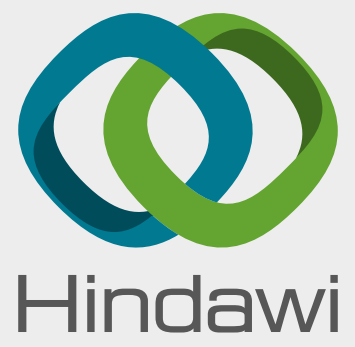

Submit your manuscripts at

www.hindawi.com
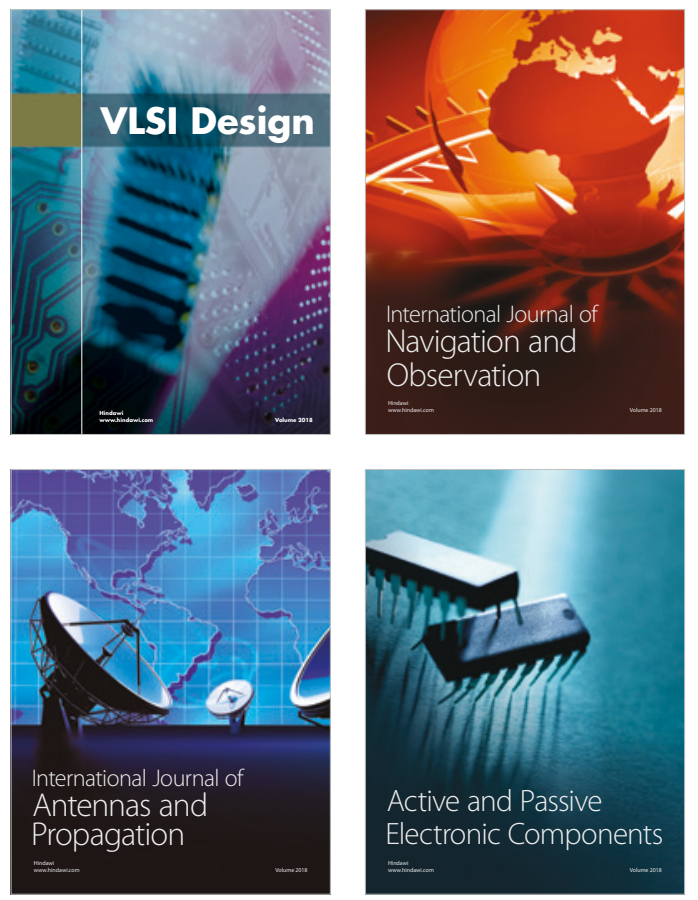
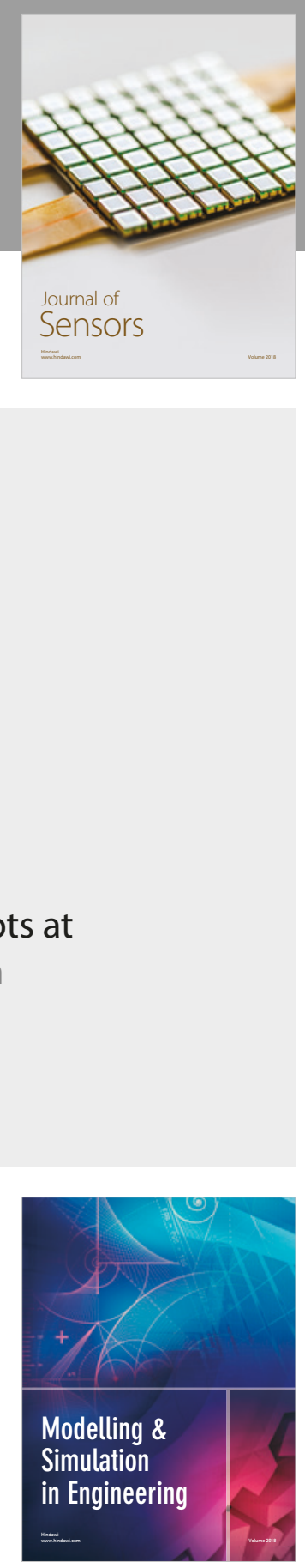

\section{Advances \\ Multimedia}
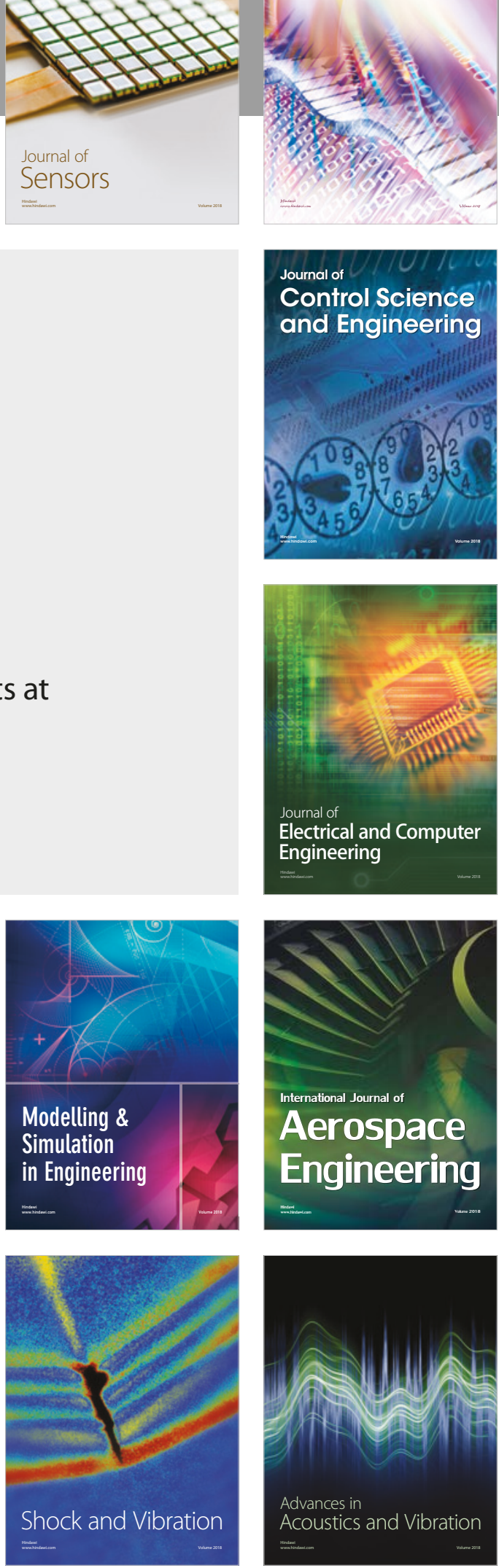